\title{
Planning for Action: The Impact of an Asthma Action Plan Decision Support Tool Integrated into an Electronic Health Record (EHR) at a Large Health Care System
}

\author{
Lindsay Kubn, MHS, PA-C, Kelly Reeves, BSN, RN, Yhenneko Taylor, PhD, \\ Hazel Tapp, PhD, Andrew McWilliams, MD, MPH, Andrew Gunter, MD, \\ Jeffrey Cleveland, MD, and Michael Dulin, $M D, P h D$
}

Introduction: Asthma is a chronic airway disease that can be difficult to manage, resulting in poor outcomes and high costs. Asthma action plans assist patients with self-management, but provider compliance with this recommendation is limited in part because of guideline complexity. This project aimed to embed an electronic asthma action plan decision support tool (eAAP) into the medical record to streamline evidence-based guidelines for providers at the point of care, create individualized patient handouts, and evaluate effects on disease outcomes.

Methods: eAAP development occurred in 4 phases: web-based prototype creation, multidisciplinary team engagement, pilot, and system-wide dissemination. Medical record and hospital billing data compared frequencies of asthma exacerbations before and after eAAP receipt with matched controls.

Results: Between December 2012 and September 2014, 5174 patients with asthma $(\sim 10 \%)$ received eAAPs. Results showed an association between eAAP receipt and significant reductions in pediatric asthma exacerbations, including $33 \%$ lower odds of requiring oral steroids $(P<.001)$, compared with controls. Equivalent adult measures were not statistically significant.

Conclusions: This study supports existing evidence that patient self-management plays an important role in reducing asthma exacerbations. We show the feasibility of leveraging technology to provide guideline-based decision support through an eAAP, addressing known challenges of implementation into routine practice. (J Am Board Fam Med 2015;28:382-393.)

Keywords: Asthma, Clinical Decision Support Systems, Electronic Health Records, Outcomes Assessment

Asthma is a chronic airway disease that can be difficult to manage, resulting in poor outcomes and

This article was externally peer reviewed.

Submitted 29 August 2014; revised 13 February 2015; accepted 23 February 2015.

From the Department of Family Medicine (LK, KR, HT, AM, MD), Dickson Advanced Analytics (YT, MD), and Department of Pediatrics (AG, JC), Carolinas HealthCare System, Charlotte, NC.

Funding: This study was funded by Carolinas HealthCare System and the Agency for Healthcare Research and Quality (grant no. R18 HS19946-01).

Conflict of interest: US patent application for "Methods and Systems for an Electronic Asthma Action Plan," application no. 61/877,491 (LEK, KR, MD); provisional patent filed September 13, 2013, and nonprovisional patent conversion filed September 14, 2014.

Corresponding author: Lindsay E. Kuhn, MHS, PA-C, Carolinas HealthCare System, Department of Family Medicine, high costs. According to 2012 data from the Centers for Disease Control and Prevention, the prevalence of asthma is increasing and is estimated to affect $8.3 \%$ of the US population. ${ }^{1}$ More than 25.5 million people are affected, of whom over 6.8 million are children. ${ }^{2}$ Unfortunately, many patients with asthma lack adequate control of their symptoms, which negatively affects their overall quality of life and leads to increased use of expensive acute care services. The burden of asthma is exceedingly high. Each year, 2 million emergency department (ED) visits, 439,000 hospitalizations, and 3,000 deaths are a result of poorly controlled asthma. ${ }^{3}$

2001 Vail Avenue, Suite 400, Mercy Medical Plaza, Charlotte, NC 28207 (E-mail: lindsay.kuhn@carolinashealthcare.org). 
An asthma action plan (AAP) is a tool designed to assist patients with self-management of their chronic disease. In fact, guidelines from the $\mathrm{Na}$ tional Heart, Lung, and Blood Institute (NHLBI) recommend that all patients with asthma be provided with a plan that includes instructions for daily management and how to recognize and handle worsening symptoms. ${ }^{4}$ AAPs are particularly helpful for patients with moderate or severe persistent asthma, a history of severe exacerbations, or poorly controlled asthma. ${ }^{4}$ While the content of each AAP may vary to some extent, ${ }^{5-7}$ typical plans outline which medications and what actions to take in the following 3 zones: (1) the "green zone," which includes medications taken every day to achieve and maintain good control; (2) the "yellow zone," which includes which rescue medications to add when asthma gets worse and when to see their provider for follow-up; and (3) the "red zone," which details what medications to take and how to seek care in the event of an asthma emergency. Previous studies demonstrate that patients receiving an AAP as part of their self-management education have higher satisfaction with their care, increased medication adherence, and fewer acute care visits compared with patients with no AAP. ${ }^{8-11}$ A Cochrane review of 36 studies showed significant reductions in both ED visits (relative risk, 0.82; 95\% confidence interval [CI], $0.73-0.94$ ) and hospitalizations (relative risk, 0.64; 95\% CI, 0.50-0.82) among patients with an AAP as part of optimal self-management compared with usual care. ${ }^{10}$

Although provision of an AAP to every patient with asthma is considered to be the standard of care, provider compliance with this recommendation has been limited. ${ }^{12-17}$ Barriers to provider compliance include lack of time, inexperience, and insufficient confidence in generating appropriate recommendations, as well as perceptions that patients may be nonadherent to AAPs or unable to self-manage. ${ }^{18,19}$ Providers also underutilize other recommendations in the NHLBI's guidelines, including assessments of asthma severity and control and the stepwise approach to managing asthma when choosing medication options for their patients. ${ }^{15,20}$ Adherence to the asthma guidelines is poor in part because of their complexity. The most recent version of the NHLBI's asthma guidelines is 440 pages long and requires providers to recall variations in the recommendations that are depen- dent on patient age, severity or level of control, and therapy step to tailor medication selection. ${ }^{4}$

The complexities and intricacies of asthma management require innovative approaches to improve quality gaps and patient outcomes. Technology can be leveraged to link and filter the guidelines to providers at the point of care, resulting in increased adherence and reduced exacerbations. By incorporating technology into providers' asthma workflow, these solutions may increase the likelihood of patients receiving guideline-based recommendations and an AAP, thus facilitating their active involvement in their own care.

The goal of this project was to develop an electronic AAP decision support tool (eAAP) within the electronic health record (EHR) that could streamline the evidence-based NHLBI guidelines for providers, while also creating an individualized instructional handout for patients to use as their selfmanagement plan. An additional aim was to prospectively evaluate the effectiveness of the eAAP's integration across the outpatient network of this large health care system. We hypothesized that patients with asthma receiving an eAAP would have fewer exacerbations after 3, 6, and 12 months compared with patients not receiving an eAAP.

\section{Methods \\ Setting}

Carolinas HealthCare System is one of the largest comprehensive networks in the United States. The fully integrated system comprises over 40 hospitals and over 900 care locations, connecting delivery of care throughout North Carolina, South Carolina, and Georgia. The health care system's 3000 physicians and advanced care practitioners, along with 15,000 nurses, participated in over 11 million encounters in $2013 .{ }^{21}$ One million patients are actively managed through the primary care network, including approximately 50,000 patients with asthma. Despite advances in care delivery, the health care system had an average of $6378 \mathrm{ED}$ visits and 1384 hospitalizations with a primary diagnosis of asthma each year from 2012 to 2014 .

\section{eAAP Development}

The eAAP was developed in 4 phases (Figure 1). Phase 1 involved the creation of a web-based eAAP prototype by researchers from the health care system's Department of Family Medicine (https:// 
Figure 1. Electronic asthma action plan decision support tool (eAAP) development phases. EHR, electronic health record.

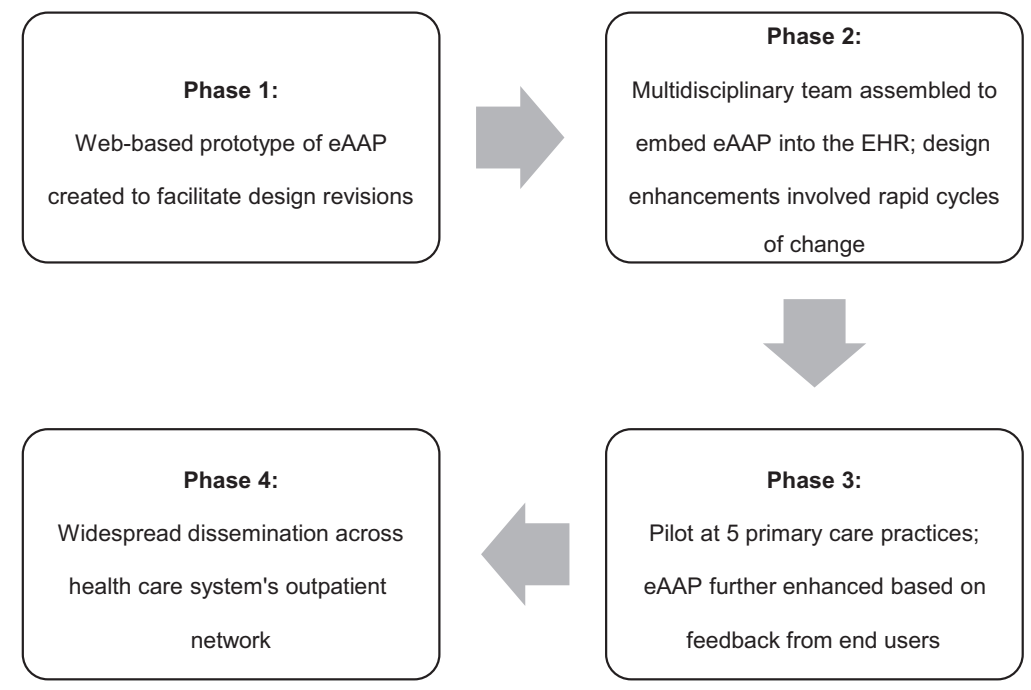

asthma.carolinashealthcare.org). This prototype facilitated the ability to make design revisions quickly and easily.

To embed this tool into the EHR, a multidisciplinary team was engaged in phase 2 . Key personnel were identified by the project's lead physician with support from system administration. Physicians, advanced care practitioners, and nurses with a special interest in asthma care were invited to participate. In addition, information technology specialists, administrators, and quality specialists from across the health care system partnered with the researchers to refine the eAAP and incorporate it into the EHR (Table 1). Because the involvement of key personnel was critically important to the project's success, the team was reassessed regularly to ensure appropriate representation.

Beginning in February 2012, the team met regularly every 4 to 6 weeks, either in person or via teleconference. Design enhancements during implementation involved rapid cycles of change using provider feedback to make modifications. Point of care convenience and ease of provider workflow was of utmost importance when modifying the tool. Each resulting output was reviewed and tested again to ensure proper functioning and positive feedback from end users. Examples of changes that went through these rapid cycle improvements for the subsequent patient handout included (1) modifications to the "green zone" verbiage for when no daily controller medication is needed; (2) specifications for
ED visit and hospital follow-up after discharge; (3) the addition of routes (inhaled or by mouth) to the medication descriptions; and (4) reformatting to print in color when applicable.

Once ready for production, the eAAP entered phase 3, where it was piloted at 5 outpatient primary care practices from December 2012 through July 2013. During this pilot stage, the development team continued to enhance the eAAP based on feedback from end users. Informed by lessons learned in the pilot, the team created a job aid and a web-based training video to assist with adoption of the tool.

Finally, in August 2013, the eAAP entered phase 4: dissemination with widespread implementation at over 100 primary care practices across the health care system. This dissemination made the eAAP available for ambulatory providers to use for any patient with asthma who, based on their clinical judgment, would benefit from its receipt. When specially requested, an eAAP team member would present on-site training sessions at individual practices to promote uptake of the tool.

The final eAAP product meets the general criteria of typical AAPs in that it instructs patients in how to manage their asthma on a daily basis and what to do in times of worsening symptoms or exacerbations. In addition, the eAAP provides (1) instantaneous determination of peak flow thresholds calculated using an algorithm based on patient demographic information, (2) guided assessment of asthma severity or control, (3) the ability to auto- 
Table 1. Ambulatory Asthma Action Plan Committee Team Members and Role Descriptions

\begin{tabular}{|c|c|c|}
\hline Team Members (n) & Credentials/Type (n) & Role Descriptions \\
\hline Physician leader (1) & $\mathrm{MD}, \mathrm{PhD}(1)$ & $\begin{array}{l}\text { Oversaw the development and implementation of the eAAP; principal investigator } \\
\text { of research project that partially funded the work }\end{array}$ \\
\hline Project manager (2) & $\begin{array}{l}\text { MBA, PT (1) } \\
\text { MHS, PA-C (1) }\end{array}$ & Coordinated team to meet goals and keep the project on track \\
\hline Content experts (2) & $\begin{array}{l}\text { MHS, PA-C (1) } \\
\text { BSN, RN (1) }\end{array}$ & $\begin{array}{l}\text { Incorporated the } 2007 \text { NHLBI asthma guidelines into the eAAP's recommended } \\
\text { stepwise treatment options }\end{array}$ \\
\hline Clinical advisors (8) & $\begin{array}{l}\text { MD (6) } \\
\text { RRT (1) } \\
\text { MSN, RN (1) }\end{array}$ & $\begin{array}{l}\text { Provided feedback regarding usability, functionality, and accessibility with regard } \\
\text { to patient care and work flow }\end{array}$ \\
\hline Programmers (5) & $\begin{array}{l}\mathrm{RN}(1) \\
\mathrm{BA} / \mathrm{BS}(5)\end{array}$ & Built the platform of the program into the EHR \\
\hline Information services (5) & $\begin{array}{l}\text { BBA, RRT (1) } \\
\text { BSN, RN (3) } \\
\text { BS (1) }\end{array}$ & Handled technical challenges blending clinical and application areas \\
\hline Quality specialists (5) & $\begin{array}{l}\text { MHS, PA-C (1) } \\
\text { BSN, RN (2) } \\
\text { MHA, CPHQ (1) } \\
\text { BS, RRT (1) }\end{array}$ & $\begin{array}{l}\text { Ensured the integration of appropriate care measures into the tool; team of } \\
\text { nurses supported its use in the field }\end{array}$ \\
\hline Administrators (2) & $\begin{array}{l}\text { MSN, RN (1) } \\
\text { BSN, RN (1) }\end{array}$ & Supported system-wide expansion \\
\hline Evaluation support (3) & $\begin{array}{l}\mathrm{PhD}(2) \\
\mathrm{MSPH}(1)\end{array}$ & Provided research and data analysis for outcomes measures \\
\hline Pilot sites (5) & $\begin{array}{l}\text { Pediatrics (2) } \\
\text { Family medicine (2) } \\
\text { Teen specialty (1) }\end{array}$ & $\begin{array}{l}\text { Provided initial feedback during the experimental phase before the system-wide } \\
\text { launch }\end{array}$ \\
\hline
\end{tabular}

eAAP, electronic asthma action plan decision support tool; EHR, electronic health record; NHLBI, National Heart, Lung, and Blood Institute.

matically populate EHR fields that satisfy asthma appropriate care expectations, (4) guideline-based decision support for medication selection, (5) electronic prescribing, and (6) generation of an individualized AAP patient handout to support selfmanagement (Figures 2 and 3).

\section{Data Collection and Analysis}

Data for evaluation of this project were obtained from the EHR system and hospital billing data. Patients with an eAAP were identified by querying the EHR each month. For each patient with a completed eAAP, a unique patient identifier and

Figure 2. Screenshot of the electronic asthma action plan decision support tool (eAAP) in the electronic health record.

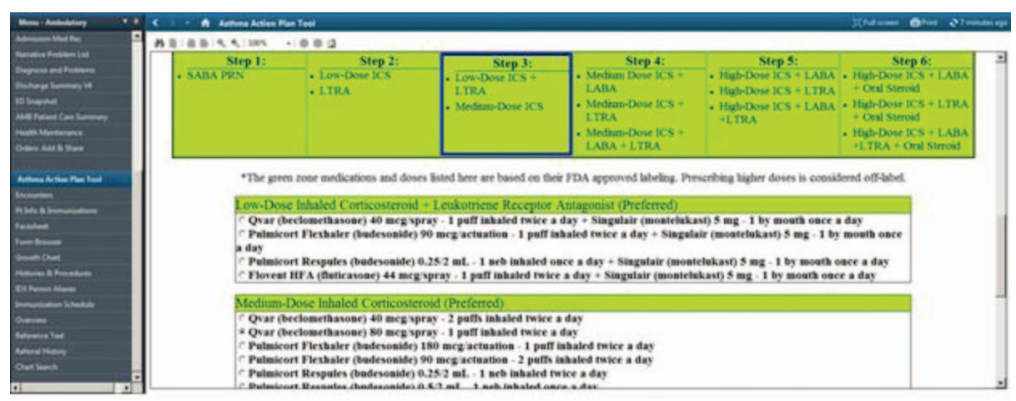

This screenshot shows the step-wise approach to medication selection of "Green Zone" daily controller options that are age and dose specific. 
the date the eAAP was performed were captured. The following binary (yes/no) events were identified as outcomes: ED visits for asthma, asthmarelated hospitalizations, and use of oral steroids for asthma exacerbations in the outpatient setting (prescription orders for prednisone, prednisolone, methylprednisolone, or dexamethasone). Asthmarelated ED visits and hospitalizations were identified from hospital billing data and included events with an International Classification of Diseases, Ninth Revision, code of 493 as the primary diagnosis. The combined measure of "any exacerbation," a binary variable indicating whether a patient had any of the 3 individual outcome measures, also was assessed.

We compared outcomes for eAAP recipients with those of nonrecipients to determine whether changes in outcomes were significantly different.
We used propensity score matching to select appropriate controls. Propensity score matching is a method to balance differences between treatment and control groups by modeling the probability of being selected to the treatment group and matching intervention participants with controls based on that probability. For this analysis, we used an established propensity matching macro based on the nearest neighbor algorithm. ${ }^{22}$ Controls were selected from a pool of 25,926 patients who attended a health care system practice where no providers had used the eAAP tool. Patients were matched based on age, race/ethnicity, gender insurance category, and the number of ED visits, hospitalizations, and oral steroid prescription orders for asthma in the previous 12 months. In addition, the month of the first eAAP was matched to the visit month for the control group to ensure visits within the same time

Figure 3. Screenshot of the electronic asthma action plan decision support tool (eAAP) patient handout for self-management.

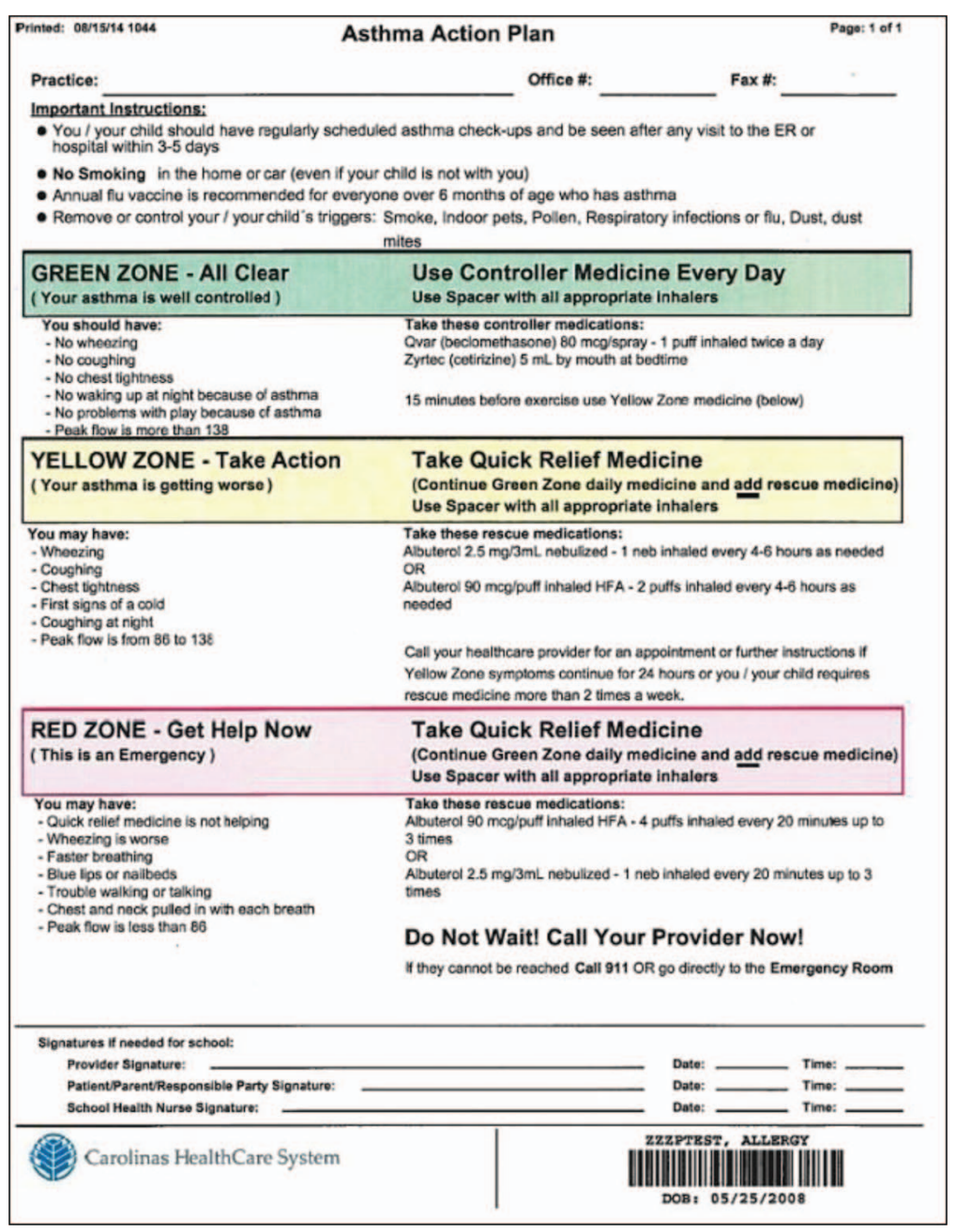


Figure 4. Electronic asthma action plan decision support tool (eAAP) usage per month across the health care system's primary care outpatient network. From December 2012 through September 2014, a total of 6484 eAAPs were completed. The tool was used at 30 to 40 outpatient practices each month by October 2013.

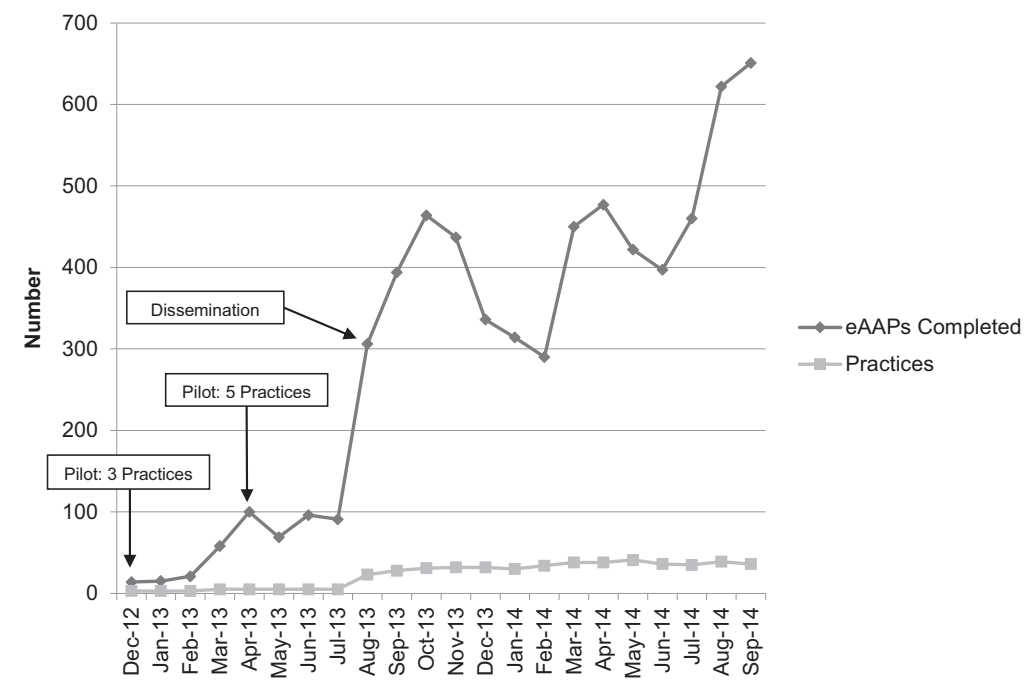

period. Propensity scores were calculated using logistic regression. The match rate for children was $65.3 \%(2783 / 4259)$ and the match rate for adults was $97.5 \%$ (892/915). The odds of primary outcomes for the eAAP recipient group versus the controls were computed using generalized estimating equations to adjust for correlation between matched samples.

The analysis also compared differences between the percentage of pediatric and adult patients with an outcome in the period before their first eAAP to the percentage of patients with an outcome in the period after the eAAP using the McNemar test statistic. Each outcome was evaluated 3, 6, and 12 months before and after the date of each patient's first eAAP. Because participants had varying follow-up times, analyses were grouped by duration of follow-up. All analyses were conducted using SAS version 9.4 (SAS, Inc., Cary, NC).

\section{Results}

Usage

From December 2012 through September 2014, 6484 eAAPs were completed across the health care system's outpatient network (Figure 4). Demographics of the 5174 unique patients with asthma who received an eAAP showed that the vast majority $(82 \%)$ were children (Table 2). Overall, patients were diverse with regard to gender, race/ethnicity, and insurance status (Table 2). The total number of
eAAP recipients represents approximately $10 \%$ of the health care system's asthma population.

Peaks in usage occurred before the beginning of the school year during the cold and influenza sea-

Table 2. Demographic Characteristics for the Sample of Patients Receiving the Electronic Asthma Action Plan Decision Support Tool $(\mathrm{N}=$ 5174)

\begin{tabular}{lcc}
\hline & $\begin{array}{c}\text { Children } \\
(0-17 \text { Years }) \\
(\mathrm{n}=4259 ; 82 \%)\end{array}$ & $\begin{array}{c}\text { Adults } \\
(\geq 18 \text { Years }) \\
(\mathrm{n}=915 ; 18 \%)\end{array}$ \\
\hline Mean age (years) & 9.3 & 40.0 \\
Gender (\%) & & \\
Female & 37.7 & 69.6 \\
Male & 62.3 & 30.4 \\
Race/ethnicity (\%) & & \\
African American & 34.0 & 42.3 \\
Caucasian & 34.0 & 41.4 \\
Hispanic/Latino & 8.4 & 3.9 \\
Asian & 1.3 & 0.2 \\
Native American & 0.1 & 0.3 \\
Multiracial & 1.5 & 0.1 \\
Other race & 3.4 & 1.9 \\
Missing & 17.3 & 9.9 \\
Insurance (\%) & & \\
Commercial & 56.0 & 53.4 \\
Medicare & N/A & 15.5 \\
Medicaid & 41.1 & 22.2 \\
Self-pay/charity & 0.0 & 0.3 \\
Other/unknown & 2.9 & 8.5 \\
\hline
\end{tabular}

N/A, not applicable. 
Table 3. Data Frequencies in the Matched Sample of Patients Receiving the Electronic Asthma Action Plan Decision Support Tool

\begin{tabular}{|c|c|c|c|c|}
\hline & \multicolumn{2}{|c|}{ Children } & \multicolumn{2}{|c|}{ Adults } \\
\hline & $\begin{array}{c}\text { eAAP } \\
(\mathrm{n}=2783)\end{array}$ & $\begin{array}{c}\text { Control } \\
(\mathrm{n}=2783)\end{array}$ & $\begin{array}{c}\text { eAAP } \\
(\mathrm{n}=892)\end{array}$ & $\begin{array}{c}\text { Control } \\
(\mathrm{n}=892)\end{array}$ \\
\hline Mean age, years (SD) & $9.3(4.3)$ & $9.3(4.6)$ & $40.1(17.1)$ & $40.2(16.6)$ \\
\hline \multicolumn{5}{|l|}{ Race/ethnicity, n (\%) } \\
\hline African American & $1,044(37.5)$ & $1,063(38.2)$ & $377(42.3)$ & $373(41.8)$ \\
\hline American Indian or Alaska Native & $15(0.5)$ & $11(0.4)$ & $8(0.9)$ & $8(0.9)$ \\
\hline Asian & $35(1.3)$ & $33(1.2)$ & $2(0.2)$ & 0 \\
\hline Caucasian & $1,220(43.8)$ & $1,219(43.8)$ & $377(42.3)$ & $404(45.3)$ \\
\hline Hispanic & $20(0.7)$ & $21(0.8)$ & $2(0.2)$ & $1(0.1)$ \\
\hline Other & $187(6.7)$ & $184(6.6)$ & $39(4.4)$ & $36(4.0)$ \\
\hline Unknown & $262(9.4)$ & $252(9.1)$ & $87(9.8)$ & $70(7.8)$ \\
\hline \multicolumn{5}{|l|}{ Insurance category, n (\%) } \\
\hline Charity & $2(0.1)$ & $1(0)$ & $2(0.2)$ & $2(0.2)$ \\
\hline Commercial & $1,452(52.2)$ & $1,432(51.5)$ & $488(54.7)$ & $513(57.5)$ \\
\hline \multicolumn{5}{|l|}{ Medicare } \\
\hline Medicaid & $1,247(44.8)$ & $1,260(45.3)$ & $202(22.6)$ & $180(20.2)$ \\
\hline Other & $38(1.4)$ & $41(1.5)$ & $8(0.9)$ & $10(1.1)$ \\
\hline Self-pay & $1(0.1)$ & & $1(0.1)$ & $1(0.1)$ \\
\hline Unknown & $44(1.6)$ & $49(1.8)$ & $49(5.5)$ & $48(5.4)$ \\
\hline \multicolumn{5}{|l|}{ Gender, n (\%) } \\
\hline Female & $1,091(39.2)$ & $1,111(39.9)$ & $620(69.5)$ & $622(69.7)$ \\
\hline Male & $1,692(60.8)$ & $1,672(60.1)$ & $272(30.5)$ & $270(30.3)$ \\
\hline $\mathrm{ED}$ visit in prior 12 months, $\mathrm{n}(\%)$ & $132(4.7)$ & $127(4.6)$ & $40(4.5)$ & $41(4.6)$ \\
\hline Hospitalization in prior 12 months, $\mathrm{n}(\%)$ & $40(1.4)$ & 45 (1.6) & $4(0.4)$ & $3(0.3)$ \\
\hline Outpatient oral steroid in prior 12 months, $\mathrm{n}(\%)$ & $716(25.7)$ & $803(28.9)$ & $181(20.3)$ & $159(17.8)$ \\
\hline \multicolumn{5}{|l|}{ Follow-up time, n (\%) } \\
\hline 3 months & $184(20.6)$ & $226(25.3)$ & $373(13.4)$ & $494(17.8)$ \\
\hline 6 months & $392(43.9)$ & 374 (41.9) & $931(33.5)$ & $780(28.0)$ \\
\hline 12 months & $316(35.4)$ & $292(32.7)$ & $1,479(53.1)$ & $1,509(54.2)$ \\
\hline
\end{tabular}

eAAP, electronic asthma action plan decision support tool; ED, emergency department; SD, standard deviation.

son in the autumn and the allergy season in the spring. Utilization also seemed to increase in 6-month intervals, consistent with the health care system's appropriate care expectation, which generates a reminder in the EHR to complete an AAP every 6 months for patients with asthma. By October 2013, 30 to 40 practices were using the eAAP each month, with new sites continually adopting the tool (Figure 4).

\section{Outcomes}

Tables 3 and 4 show the distribution of characteristics and outcomes for matched samples of children and adults. Compared with the controls, eAAP recipients did not differ significantly in the odds of ED visits or hospitalizations for asthma at 3, 6, or 12 months (Table 5). Children receiving an
eAAP, however, had $33 \%$ lower odds of receiving an oral steroid for asthma (12-month odds ratio [OR], 0.67; 95\% CI, 0.56-0.81). The combined exacerbation outcome was also significant (12month OR, 0.73; 95\% CI, 0.61-0.87). Equivalent measures for adults were not statistically significant.

In addition, the results showed an association between receipt of an eAAP and a significant reduction in pediatric asthma exacerbations at 3, 6, and 12 months using pre/post analyses (Table 6). Asthma-related ED visits declined by $41 \%$ at 3 months $(P<.05), 32 \%$ at 6 months $(P<.05)$, and $40 \%$ at 12 months $(P<.001)$ after children received an eAAP. Children also received fewer oral steroids, a marker of exacerbation, after receiving an eAAP; use decreased by $51 \%$ at 3 months $(P<$ 
Table 4. Acute Asthma Outcome Frequencies in the Matched Sample of Patients Receiving the Electronic Asthma Action Plan Decision Support Tool

\begin{tabular}{|c|c|c|c|c|}
\hline \multirow{2}{*}{$\begin{array}{l}\text { Outcomes by Follow-up } \\
\text { Time }\end{array}$} & \multicolumn{2}{|c|}{ Children } & \multicolumn{2}{|c|}{ Adults } \\
\hline & $\operatorname{eAAP}(\mathrm{n}=2783)$ & Control $(\mathrm{n}=2783)$ & eAAP $(\mathrm{n}=892)$ & Control $(\mathrm{n}=892)$ \\
\hline \multicolumn{5}{|l|}{$\mathrm{ED}$ visit, $\mathrm{n}(\%)$} \\
\hline 3 months after & $31(1.1)$ & $26(0.9)$ & $14(1.6)$ & $10(1.1)$ \\
\hline 6 months after & $56(2.0)$ & $53(1.9)$ & $20(2.2)$ & $18(2.0)$ \\
\hline 12 months after & $89(3.2)$ & $84(3.0)$ & $29(3.3)$ & $23(2.6)$ \\
\hline \multicolumn{5}{|l|}{ Hospitalization, n (\%) } \\
\hline 3 months after & $6(0.2)$ & $11(0.4)$ & $2(0.2)$ & $1(0.1)$ \\
\hline 6 months after & $12(0.4)$ & $15(0.5)$ & $3(0.3)$ & $4(0.4)$ \\
\hline 12 months after & $16(0.6)$ & $18(0.6)$ & $6(0.7)$ & $4(0.4)$ \\
\hline \multicolumn{5}{|c|}{ Outpatient oral steroid, n (\%) } \\
\hline 3 months after & $162(5.8)$ & $223(8.0)$ & $62(7.0)$ & $76(8.5)$ \\
\hline 6 months after & $237(8.5)$ & $297(10.7)$ & $88(9.9)$ & $93(10.4)$ \\
\hline 12 months after & $219(7.9)$ & $311(11.2)$ & $60(6.7)$ & $60(6.7)$ \\
\hline \multicolumn{5}{|l|}{ Any exacerbation, n (\%) } \\
\hline 3 months after & $194(7.0)$ & $250(9.0)$ & $76(8.5)$ & $84(9.4)$ \\
\hline 6 months after & $282(10.1)$ & $329(11.8)$ & $105(11.8)$ & $107(12.0)$ \\
\hline 12 months after & $261(9.4)$ & $344(12.4)$ & $76(8.5)$ & $70(7.8)^{*}$ \\
\hline
\end{tabular}

*Counts for outcomes 3, 6, and 12 months after the intervention include only patients with enough follow-up to capture those outcomes. eAAP, electronic asthma action plan decision support tool; ED, emergency department.

$.001), 41 \%$ at 6 months $(P<.001)$, and $34 \%$ at 12 months $(P<.001)$. Pediatric inpatient hospital stays for asthma demonstrated a similar decreasing trend; however, significance was not reached be- cause of the low incidence of hospitalizations. Among children with at least 12 months of follow-up ( $\mathrm{n}=1925)$, overall asthma exacerbation rates dropped by $34 \%(P<.001)$ (Table 6).

Table 5. Odds Ratios Comparing the Odds of Acute Asthma Outcome Events Among Recipients of the Electronic Asthma Action Plan Decision Support Tool Versus Controls

\begin{tabular}{|c|c|c|c|c|}
\hline \multirow[b]{2}{*}{ Outcomes by Follow-up Time } & \multicolumn{2}{|c|}{ Children } & \multicolumn{2}{|l|}{ Adults } \\
\hline & Odds Ratio (95\% CI) & $P$ Value & Odds Ratio (95\% CI) & $P$ Value \\
\hline \multicolumn{5}{|l|}{ ED visit } \\
\hline 3 months after & $1.19(0.17-2.00)$ & .501 & $1.41(0.62-3.20)$ & .416 \\
\hline 6 months after & $1.03(0.69-1.55)$ & .869 & $1.14(0.57-2.30)$ & .709 \\
\hline 12 months after & $1.00(0.67-1.49)$ & .998 & $1.53(0.79-2.94)$ & .207 \\
\hline \multicolumn{5}{|l|}{ Hospitalization } \\
\hline 3 months after & $0.54(0.20-1.48)$ & .232 & $2.00(0.18-22.16)$ & .571 \\
\hline 6 months after & $1.05(0.43-2.60)$ & .908 & $0.23(0.03-2.11)$ & .195 \\
\hline 12 months after & $1.17(0.42-3.23)$ & .765 & $0.61(0.10-3.71)$ & .594 \\
\hline \multicolumn{5}{|l|}{ Outpatient oral steroid } \\
\hline 3 months after & $0.71(0.58-0.87)$ & .001 & $0.80(0.57-1.13)$ & .209 \\
\hline 6 months after & $0.73(0.61-0.88)$ & $<.001$ & $0.88(0.64-1.20)$ & .402 \\
\hline 12 months after & $0.67(0.56-0.81)$ & $<.001$ & $0.91(0.62-1.35)$ & .652 \\
\hline \multicolumn{5}{|l|}{ Any exacerbation } \\
\hline 3 months after & $0.76(0.63-0.92)$ & .005 & $0.90(0.65-1.24)$ & .502 \\
\hline 6 months after & $0.79(0.67-0.94)$ & .006 & $0.91(0.68-1.22)$ & .592 \\
\hline 12 months after & $0.73(0.61-0.87)$ & $<.001$ & $1.02(0.71-1.45)$ & .923 \\
\hline
\end{tabular}

CI, confidence interval; ED, emergency department. 
Table 6. Acute Asthma Outcomes Among Patients Receiving the Electronic Asthma Action Plan Decision Support Tool by Time Since First Use of the Tool

\begin{tabular}{|c|c|c|c|c|c|c|}
\hline \multirow[b]{2}{*}{ Outcomes } & \multicolumn{6}{|c|}{ Follow-up Time } \\
\hline & 3 Months before & 3 Months after & 6 Months before & 6 Months after & 12 Months before & 12 Months after \\
\hline Children, n (\%) & \multicolumn{2}{|c|}{3 Months (n = 4,259) } & \multicolumn{2}{|c|}{6 Months $(\mathrm{n}=3,358)$} & \multicolumn{2}{|c|}{12 Months $(\mathrm{n}=1,925)$} \\
\hline ED visit & $72(1.7)$ & $44(1.0)^{*}$ & $85(2.5)$ & $57(1.7)^{*}$ & $93(4.8)$ & $55(2.9)^{\dagger}$ \\
\hline Hospitalization & $16(0.4)$ & $8(0.2)^{\ddagger}$ & $21(0.6)$ & $12(0.4)$ & $18(0.9)$ & $9(0.5)^{\ddagger}$ \\
\hline Outpatient oral steroid & $467(11.0)$ & $232(5.4)^{\dagger}$ & $510(15.2)$ & $303(9.0)^{\dagger}$ & $413(21.5)$ & $273(14.2)^{\dagger}$ \\
\hline Any exacerbation & $537(12.6)$ & $277(6.5)^{\dagger}$ & $585(17.4)$ & $357(10.6)^{\dagger}$ & $484(25.1)$ & $319(16.6)^{\dagger}$ \\
\hline Adults, n (\%) & \multicolumn{2}{|c|}{3 Months $(\mathrm{n}=915)$} & \multicolumn{2}{|c|}{6 Months $(\mathrm{n}=717)$} & \multicolumn{2}{|c|}{12 Months $(\mathrm{n}=316)$} \\
\hline ED visit & $17(1.9)$ & $15(1.6)$ & $19(2.7)$ & $17(2.4)$ & $19(6.0)$ & $19(6.0)$ \\
\hline Hospitalization & $1(0.1)$ & $2(0.2)$ & $1(0.1)$ & $1(0.1)$ & $3(1.0)$ & $2(0.6)$ \\
\hline Outpatient oral steroid & $106(11.6)$ & $63(6.9)^{\dagger}$ & $98(13.7)$ & $89(12.4)$ & $56(17.7)$ & $60(19.0)$ \\
\hline Any exacerbation & $117(12.8)$ & $78(8.5)^{*}$ & $112(15.6)$ & $106(14.8)$ & $70(22.2)$ & $76(24.1)$ \\
\hline
\end{tabular}

Change from prior period determined using the McNemar test:, ${ }^{*} P<.05,{ }^{\dagger} P<.001,{ }^{\ddagger} P<.10$.

ED, emergency department.

Equivalent pre/post measures for adults were not statistically significant at 6 or 12 months, likely because of the smaller sample size; however, a $41 \%$ decrease in outpatient oral steroids $(P<.001)$ and a $34 \%$ reduction in any exacerbation $(P<.05)$ occurred 3 months after receiving an eAAP (Table 6).

Post hoc power analyses revealed $<40 \%$ power to detect the observed differences in ED visits and hospitalizations in our matched pediatric sample. The matched adult sample provided $69 \%$ power to detect differences in inpatient stays but $<40 \%$ power for all other outcomes.

\section{Discussion}

Significant reductions in asthma exacerbationrelated outcomes, namely, oral steroid prescription orders, were seen in association with receipt of an eAAP among children, but not adults, in the outpatient setting of a large health care system. The majority of plans (82\%) were created for children. This higher portion of pediatric recipients was an expected finding because it is customary for schools to request or require a copy of the AAP for their records, where it is used as an order for medication administration during exacerbations.

This eAAP not only satisfies the traditional elements of basic AAPs but also leverages technology to improve the efficiency of care delivery and adherence to evidence-based guidelines with decision support capabilities to improve asthma control. Furthermore, because this eAAP is embedded in the EHR, workflow is optimized for busy providers, and continuity of care is achieved across the health care system.

Little in the current literature describes the development, integration, and evaluation of an eAAP. Roberts et $\mathrm{al}^{23}$ developed an electronic pictorial $\mathrm{AAP}$ and incorporated it into a separate software package but not the EHR. Hanson et $\mathrm{al}^{24}$ studied the electronic sharing of AAPs between providers and schools through a secure portal but did not evaluate disease-specific outcomes. This novel evaluation of asthma outcomes associated with use of an EHR-embedded decision support tool adds to knowledge of the effectiveness of these tools to improve disease outcomes.

The integration of clinical decision support within the EHR is becoming increasingly popular as a result of meaningful use legislation, and future medical practice is anticipated to progressively tie financial incentives to clinical outcomes. ${ }^{25}$ Studies show improvements in preventive care services, appropriate care, clinical outcomes, and cost when providers have access to current medical knowledge and evidence-based guidance at the point of care..$^{25-28}$ Other examples of EHR-based clinical decision support include interventions around diabetes ${ }^{29}$ and bipolar disorder with depression. ${ }^{30}$

If the use of an eAAP results in better asthma control and fewer asthma exacerbations, as these results suggest, the impact on the cost of care could be significant. Direct health care costs for patients with asthma vary considerably depending on their 
level of asthma control. In a study of Kaiser Permanente's Southern California System, there was a $\$ 3499$ difference in direct costs for those with uncontrolled versus controlled asthma: \$6797 versus \$3298, respectively. ${ }^{31}$ A national study by Ivanova et $\mathrm{al}^{32}$ found a difference of $\$ 4212$, and Barnett and Nurmagambetov $^{33}$ found a difference of $\$ 3259$ using the 2004 Medical Expenditure Panel Survey. ${ }^{34}$ Extrapolating from these numbers, it can be assumed that asthma control saves approximately $\$ 4000$ per patient. Thus, on a regional level, Carolinas HealthCare System, which cares for over 50,000 patients with asthma, could potentially see large savings associated with improved outcomes. Much broader financial savings implications are possible for payors and the larger US health care system.

A limitation of this study is that the observational design yielded association, not causality, between receipt of an eAAP and improved disease outcomes for children with asthma. Comparisons with matched control showed significantly lower odds of children requiring oral steroids for acute exacerbations 3, 6, and 12 months after receipt of an eAAP, but no change in ED visit or hospitalization rates was demonstrated because there was insufficient power to detect small differences. A randomized controlled trial, which was not performed because of a lack of resources, would strengthen the evaluation.

Nevertheless, the downward trends in acute care visits persisted across the 3 different observation periods in pre/post analyses. Since 2010, asthma has been a disease of interest at this health care system, with various asthma initiatives being explored simultaneously. A related limitation is the challenge of differentiating the impact of the eAAP on asthma exacerbations while other concurrent asthma management projects were underway. Concurrent projects included deployment of an integrated approach to asthma care in which a team of quality nurses focused on guiding practices in the use of EHR asthma appropriate care and an asthma shared decision making intervention located at 6 underserved practices. ${ }^{35,36}$

To promote high-quality care for patients with asthma in the ambulatory setting, the health care system monitors several appropriate care expectations. These expectations, seen as alerts in a "health maintenance module," are easily viewable on the opening summary page in the EHR of a patient with asthma. Some alerts are measured and reported back to providers with regard to their quality goals, which may be tied to compensation, whereas others, including biannual AAP completion satisfied by the eAAP, are currently not measured. Having no incentive for completion of this expectation may partly explain the relative underuse of the eAAP in comparison to the health care system's overall asthma population.

Pediatric providers may be more aware of the optional AAP expectation because asthma is at this time the only disease state monitored for children at the health care system. For this reason, extra attention may be paid to the completion of both the measured and unmeasured expectations, including the eAAP for children. Adult patients, on the other hand, may have numerous alerts in their health maintenance modules, depending on their comorbid conditions, prompting providers to prioritize completion of the measured expectations and thus explaining the relative underutilization of the eAAP in adults.

Management of asthma in adults not only is challenging because of complicating comorbidities but also is contingent on various behavioral factors. Minimizing exposure to known triggers, avoiding smoking tobacco products, and adhering to the prescribed regimen, namely, inhaled corticosteroids, are paramount to achieving successful control. ${ }^{37}$ Poor adherence often is associated with difficulties with inhaler devices, complicated regimens, side effects, and cost. ${ }^{38}$ These difficulties, in addition to the small sample size, may explain why adults achieved less impact of receiving an eAAP.

Finally, there may be instances in which patients are incorrectly diagnosed or coded with asthma, leading them to have asthma appropriate care expectations erroneously included in their health maintenance modules. Perhaps some children had wheezing associated with a respiratory illness, or some adults have chronic obstructive pulmonary disease as opposed to asthma. Providers may choose not to perform an eAAP in these cases, introducing selection bias. As currently designed, whether to complete an eAAP for an individual patient is at the providers' discretion, based on their clinical assessment.

Currently, the eAAP is used only in the ambulatory setting. Further expansion of the eAAP into the ED and hospital environments is planned to 
create one unified approach to asthma care that is linked across all care settings within the health care system. It is anticipated that this expansion will help to achieve quality measures in the acute care locations. Since 2007, the Joint Commission has mandated freestanding children's hospitals to report compliance with 3 Children's Asthma Care (CAC) core quality measures for accreditation and to improve asthma care. ${ }^{39,40}$ The first 2 core measures assess compliance with evidence-based treatments for acute exacerbations, including the use of rescue inhalers and systemic corticosteroids. CAC-3 assesses compliance with preventive asthma measures to reduce readmissions, measured by the presence of a comprehensive home management plan of care, otherwise known as an AAP, at hospital discharge. ${ }^{40}$ The CAC-3 measure has historically fallen short of benchmarks both nationally and locally, a gap that has been attributed to paper AAPs being difficult to relocate in the EHR when audited..$^{39,41,42}$ The eAAP has the potential to increase compliance with CAC-3 by being fully embedded in the EHR. Moreover, the connection of a patient's single AAP through the EHR to patient portals or through health information exchanges may further enhance patient engagement and continuity of care from the acute to the ambulatory settings.

\section{Conclusions}

This study supports existing evidence that patient self-management plays an important role in reducing asthma exacerbations. In addition, we show the feasibility of leveraging technology to provide guideline-based decision support through an eAAP, addressing known challenges of implementation into routine practice.

The authors gratefully acknowledge the Ambulatory Asthma Action Plan Committee for their commitment to and support of this project; the 5 pilot practices for testing the tool early on in development and providing crucial feedback; our acute care physician champions Dr. Matthew Sullivan and Dr. Cheryl Courtlandt; Dr. Jewell Carr and Dr. Thomas Ludden for their assistance in manuscript preparation; and Dr. Beau Mack, a former family medicine resident, who helped develop the webbased prototype.

\section{References}

1. Centers for Disease Control and Prevention. Current asthma prevalence percents by age, United States: National Health Interview Survey, 2012. Available from: http://www.cdc.gov/asthma/nhis/ 2012/table4-1.htm. Accessed August 13, 2014.
2. Centers for Disease Control and Prevention. Current asthma population estimates, in thousands by age, United States: National Health Interview Survey, 2012. Available from: http://www.cdc.gov/ asthma/nhis/2012/table3-1.htm. Accessed August 13, 2014.

3. Akinbami LJ, Moorman JE, Bailey C, et al. Trends in asthma prevalence, health care use, and mortality in the United States, 2001-2010. NCHS Data Brief 2012;(94):1-8.

4. National Heart, Lung, and Blood Institute. National Asthma Education and Prevention Program. Expert Panel Report 3: Guidelines for the diagnosis and management of asthma. Full report 2007. Available from: http://www.nhlbi.nih.gov/guidelines/asthma/ asthgdln.pdf. Accessed April 10, 2014.

5. Yin HS, Gupta RS, Tomopoulos S, et al. Readability, suitability, and characteristics of asthma action plans: examination of factors that may impair understanding. Pediatrics 2013;131:e116-26.

6. Rank MA, Volcheck GW, Li JT, Patel AM, Lim KG. Formulating an effective and efficient written asthma action plan. Mayo Clin Proc 2008;83: 1263-70.

7. Gibson PG, Powell H. Written action plans for asthma: an evidence-based review of the key components. Thorax 2004;59:94-9.

8. Patel MR, Valerio MA, Sanders G, Thomas LJ, Clark NM. Asthma action plans and patient satisfaction among women with asthma. Chest 2012;142: 1143-9.

9. Zemek RL, Bhogal SK, Ducharme FM. Systematic review of randomized controlled trials examining written action plans in children: what is the plan? Arch Pediatr Adolesc Med 2008;162:157-63.

10. Gibson PG, Powell H, Coughlan J, et al. Self-management education and regular practitioner review for adults with asthma. Cochrane Database Syst Rev 2003;(1):CD001117.

11. Ducharme FM, Zemek RL, Chalut D, et al. Written action plan in pediatric emergency room improves asthma prescribing, adherence, and control. Am J Respir Crit Care Med 2011;183:195-203.

12. Hartert TV, Windom HH, Peebles RS Jr, Freidhoff LR, Togias A. Inadequate outpatient medical therapy for patients with asthma admitted to two urban hospitals. Am J Med 1996;100:386-94.

13. Taylor DM, Auble TE, Calhoun WJ, Mosesso VN Jr. Current outpatient management of asthma shows poor compliance with International Consensus Guidelines. Chest 1999;116:1638-45.

14. Kaferle JE, Wimsatt LA. A team-based approach to providing asthma action plans. J Am Board Fam Med 2012;25:247-9.

15. Wisnivesky JP, Lorenzo J, Lyn-Cook R, et al. Barriers to adherence to asthma management guidelines among inner-city primary care providers. Ann Allergy Asthma Immunol 2008;101:264-70. 
16. Rastogi D, Shetty A, Neugebauer R, Harijith A. National Heart, Lung, and Blood Institute guidelines and asthma management practices among inner-city pediatric primary care providers. Chest 2006;129:619-23.

17. Cabana MD, Rand CS, Becher OJ, Rubin HR. Reasons for pediatrician nonadherence to asthma guidelines. Arch Pediatr Adolesc Med 2001;155:1057-62.

18. Gupta S, Wan FT, Hall SE, Straus SE. An asthma action plan created by physician, educator and patient online collaboration with usability and visual design optimization. Respiration 2012;84:406-15.

19. Partridge MR. Written asthma action plans. Thorax 2004;59:87-8.

20. Elward K, Blackburn B, Peterson LE, Greenawald M, Hagen MD. Improving quality of care and guideline adherence for asthma through a group self-assessment module. J Am Board Fam Med 2014;27:391-8.

21. Carolinas HealthCare System. 2013 Value report: differentiable care and value within one integrated system. Available from: http://www.carolinashealthcare.org/ documents/chs/2013-value-report.pdf. Accessed March 16, 2015.

22. Rassen JA, Doherty M, Huang W, Schneeweiss S. Pharmacoepidemiology toolbox. Boston: Division of Pharmacoepidemiology \& Pharmacoeconomics, Department of Medicine, Brigham and Women's Hospital, Harvard Medical School. Available from: http://www.drugepi.org/dope-downloads/. Accessed September 26, 2013.

23. Roberts NJ, Evans G, Blenkhorn P, Partridge MR. Development of an electronic pictorial asthma action plan and its use in primary care. Patient Educ Couns 2010;80:141-6.

24. Hanson TK, Aleman M, Hart L, Yawn B. Increasing availability to and ascertaining value of asthma action plans in schools through use of technology and community collaboration. J School Health 2013;83:915-20.

25. Murphy EV. Clinical decision support: effectiveness in improving quality processes and clinical outcomes and factors that may influence success. Yale J Biol Med 2014;87:187-97.

26. Feldstein A, Elmer PJ, Smith DH, et al. Electronic medical record reminder improves osteoporosis management after a fracture: a randomized, controlled trial. J Am Geriatr Soc 2006;54:450-7.

27. Heidenreich PA, Gholami P, Sahay A, Massie B, Goldstein MK. Clinical reminders attached to echocardiography reports of patients with reduced left ventricular ejection fraction increase use of betablockers: a randomized trial. Circulation. 2007;115: 2829-34.

28. Bright TJ, Wong A, Dhurjati R, et al. Effect of clinical decision-support systems: a systematic review. Ann Intern Med 2012;157:29-43.

29. Gunathilake W, Gunawardena S, Fernando R, Thomson G, Fernando D. The impact of a decision support tool linked to an electronic medical record on glycemic control in people with type 2 diabetes. J Diabetes Sci Technol 2013;7:653-9.

30. Gill JM, Chen YX, Grimes A, Klinkman MS. Using electronic health record-based tools to screen for bipolar disorder in primary care patients with depression. J Am Board Fam Med 2012;25:283-90.

31. Anderko L, Bartz C, Lundeen S. Wellness for a lifetime: improving lifestyle behaviors of low-income, ethnically diverse populations. Ann Fam Med 2005;3(Suppl 2):S35-6.

32. Ivanova JI, Bergman R, Birnbaum HG, Colice GL, Silverman RA, McLaurin K. Effect of asthma exacerbations on health care costs among asthmatic patients with moderate and severe persistent asthma. J Allergy Clin Immunol 2012;129:1229-35.

33. Barnett SB, Nurmagambetov TA. Costs of asthma in the United States: 2002-7. J Allergy Clin Immunol 2011;127:145-52.

34. Zeiger RS, Hay JW, Contreras R, et al. Asthma costs and utilization in a managed care organization. $\mathrm{J}$ Allergy Clin Immunol 2008;121:885-92.e5.

35. Tapp H, Hebert L, Dulin M. Comparative effectiveness of asthma interventions within a practice based research network. BMC Health Serv Res 2011;11:188.

36. Tapp H, Kuhn L, Alkhazraji T, et al. Adapting community based participatory research (CBPR) methods to the implementation of an asthma shared decision making intervention in ambulatory practices. J Asthma 2014;51:380-90.

37. Lavoie KL, Moullec G, Lemiere C, et al. Efficacy of brief motivational interviewing to improve adherence to inhaled corticosteroids among adult asthmatics: results from a randomized controlled pilot feasibility trial. Patient Prefer Adherence 2014;8:1555-69.

38. Makela MJ, Backer V, Hedegaard M, Larsson K. Adherence to inhaled therapies, health outcomes and costs in patients with asthma and COPD. Respir Med 2013;107:1481-90.

39. Zipkin R, Schrager SM, Keefer M, Marshall L, Wu $\mathrm{S}$. Improving home management plan of care compliance rates through an electronic asthma action plan. J Asthma 2013;50:664-71.

40. Nkoy FL, Fassl BA, Wolfe D, Colling D, Hales JW, Maloney CG. Sustaining compliance with pediatric asthma inpatient quality measures. AMIA Annu Symp Proc 2010;2010:547-51.

41. The Joint Commission. Improving America's hospitals: the Joint Commission's Annual Report on Quality and Safety. 2013. Available from: http:// www.jointcommission.org/improving_americas_ hospitals_the_joint_commissions_annual_report_ on_quality_and_safety_2013/. Accessed March 9, 2015.

42. Tolomeo C, Shiffman R, Bazzy-Asaad A. Electronic medical records in a sub-specialty practice: one asthma center's experience. J Asthma 2008;45:849-51. 